\title{
Reutilização simulada de produtos médico-hospitalares de uso único, submetidos à esterilização com óxido de etileno
}

\author{
Mônica Valero da Silva ${ }^{1,2 *}$, Terezinha de Jesus A. Pinto ${ }^{2}$ \\ ${ }^{1}$ Faculdade de Ciências da Saúde, Departamento de Farmácia, Fundação Universidade de Brasília, ${ }^{2}$ Departamento \\ de Farmácia,Faculdade de Ciências Farmacêuticas, Universidade de São Paulo
}

*Correspondência:

M. V. Silva

Campus Universitário Darcy Ribeiro/

UnB - Asa Norte

70910-900, Brasília, DF, Brasil.

E-mail: mvalero2@hotmail.com
Objetivando avaliar o risco/beneficio da reutilização de produtos médico-hospitalares de uso único, aplicaram-se dois desafios simulados: um com esporos de Bacillus subtilis e outro com endotoxina bacteriana da Escherichia coli, em corpos de prova representados por cateteres intravenosos, torneira três vias e tubos de traqueostomia. Estes foram submetidos a ciclos de reprocessamentos simulados, sendo 300 unidades intencionalmente contaminadas com $\mathrm{B}$. subtilis ( $10^{7}$ ufc/unidade) e outro grupo de 90 unidades contaminadas com endotoxina bacteriana (200 UE/ unidade). Os corpos de prova contaminados com B. subtilis foram lavados, enxaguados, secados e esterilizados em ETO/CFC 12:88. Os contaminados com endotoxina bacteriana foram submetidos à secagem, embalados e esterilizados. Após cada ciclo, dez unidades de cada corpo de prova contaminadas com B. subtilis foram avaliadas por contagem microbiana, testes de esterilidade, citotoxidade in vitro e microscopia eletrônica de varredura. Dos contaminados com endotoxina bacteriana, três de cada foram submetidos ao teste turbidimétrico após cada ciclo. No desafio com B. subtilis, verificou-se a presença de carga viável até $10^{3}$ ufc e ocorreram danos na integridade física dos corpos de prova após o décimo reprocessamento, mas não se evidenciou toxicidade. No outro desafio, verificou-se aumento progressivo da porcentagem recuperada de endotoxina bacteriana. Frente a estes resultados, tal prática não é recomendada.

\section{INTRODUÇÃO}

Reutilizar ou não um produto médico-hospitalar fabricado para uso único tem sido um questionamento mundial. Há aqueles que defendem essa prática visando à economia de custos obtida com o reprocessamento, uma vez que es- ses produtos são bastante onerosos para as instituições hospitalares. Entretanto, muitos são aqueles que questionam a falta de segurança no reprocessamento destes produtos, pois nem sempre os métodos de limpeza e esterilização são eficazes para eliminar a presença de contaminantes, os quais podem gerar problemas graves para o paciente que venha 
a fazer uso de um produto reutilizado e reprocessado, como as contaminações bacterianas e as reações pirogênicas.

Estudos realizados enfocando a padronização e a validação da limpeza dos produtos a serem reprocessados têm sido publicados constantemente por pesquisadores atuantes nessa área de reprocessamento de materiais de uso único. Existe, pois, a necessidade de garantir que a limpeza empregada, seja ela manual ou automatizada, alcance o objetivo principal, que é eliminar possíveis presenças de resíduos protéicos que possam gerar focos de contaminação, assim como a formação de biofilmes aderidos ao lúmen de cateteres (Alfa, Nemes, 2003).

A validação do processo de limpeza é de extrema importância para que se possa garantir a eficácia desse procedimento. Todavia, falar em validação significa falar em reprodutibilidade do processo e isso muitas vezes não ocorre, pois o reprocessamento dos produtos médico-hospitalares freqüentemente é terceirizado por empresas que recebem esses produtos para reprocessamento, mas não aplicam os testes cabíveis com o fim de assegurar que aqueles produtos, após reprocessamento, estarão isentos de bactérias viáveis e principalmente de pirogênios. A validação de um processo de limpeza varia de acordo com o produto médico-hospitalar a reprocessar, uma vez que a conformidade física desses produtos varia de um para outro (Pinto, Graziano, 2000; Lacerda, Silva, 1992).

Simular um processo é maneira de avaliar a eficácia do processo empregado, como também de verificar qual o melhor caminho de alcançar baixos índices de contaminação que não provoquem reações ou infecções no paciente. Com base nesse fato, muitos pesquisadores têm publicado trabalhos que apresentam resultados assegurando a reutilização destes produtos fabricados para uso único por mais de uma vez, desde que sejam submetidos a um processo de limpeza e esterilização adequadamente validado e padronizado (Blomström-Lundqvist, 1999; Plante et al., 1994; Berenger, Ferguson, 2004).

Levando-se em consideração o problema da reutilização de produtos médico-hospitalares de uso único, empregaram-se desafios simulados para alguns tipos de produtos hospitalares que não são, necessariamente, reutilizados rotineiramente em instituições hospitalares, mas que podem simular as características físicas daqueles rotineiramente reprocessados; por isso, durante o trabalho, eles são mencionados como corpos de prova.

\section{MATERIAL E MÉTODOS}

Os materiais de estudo para o desafio com Bacillus subtilis constituíram-se em produtos médico-hospitalares de uso único de diferentes tipos: 100 unidades de torneiras três vias, 100 tubos de traqueostomia (diâmetro interno 8,0 $\mathrm{mm}$ e externo $11,2 \mathrm{~mm}, \mathrm{FR}-33$ ) com balonete e 100 cateteres intravenosos (diâmetro 1,60 mm, 14G e comprimento de $30,4 \mathrm{~cm}$ ), todos cedidos por produtor nacional (Tecnobio). Para o desafio com endotoxina bacteriana, os produtos foram os mesmos, sendo alteradas apenas as quantidades de cada um deles, ou seja, 30 unidades para cada tipo de produto citado anteriormente.

Durante cada desafio, também foram utilizadas unidades-controle, conforme recebidas pelo fornecedor.

\section{MÉTODOS}

\section{Desafio com esporos de Bacillus subtilis var. niger ATCC 9372}

Preparou-se suspensão padronizada de esporos de Bacillus subtilis var. niger numa proporção de carga microbiana de $10^{8} \mathrm{ufc} / \mathrm{mL}$, conforme mencionado em literatura (Pinto, Saito, 1992; Pinto, Saito, Iossif, 1994; European Pharmacopoeia, 1999; Pinto, Kaneko, Ohara, 2000; United States Pharmacopeia, 2000). A partir desta suspensão padronizada, inoculou-se volume de $0,1 \mathrm{~mL}\left(10^{7} \mathrm{ufc}\right)$ em cada corpo de prova, sendo que no tubo de traqueostomia, a inoculação ocorreu no interior do lúmen e na área externa do tubo, totalizando $0,2 \mathrm{~mL}$ da suspensão de esporos.

Esses corpos de prova contaminados foram submetidos à secagem numa capela para manipulação asséptica durante 96 horas. Após secagem, iniciou-se a lavagem de todos os corpos de prova com detergente enzimático (DEIV 3E) a 0,5\% (v/v) em água recentemente destilada e apirogênica, conforme teste de LAL de gelificação empregado (United States Pharmacopeia, 2000). Após uma hora de exposição dos corpos de prova à solução de limpeza, iniciou-se um fluxo interno, com seringa de vidro esterilizada de $50 \mathrm{~mL}$, desta solução em cada corpo de prova quatro vezes consecutivas; em seguida, efetuou-se o enxágüe em três cubas com água destilada apirogênica, fazendo-se na segunda cuba um fluxo interno em cada corpo de prova com outra seringa de vidro de $50 \mathrm{~mL}$, esterilizada, repetindo-se o processo duas vezes para cada unidade. Os corpos de prova permaneceram em repouso durante 30 minutos na terceira cuba.

Após lavagem, os corpos de prova foram expostos à secagem em capela para manipulação asséptica durante 48 horas. Em seguida, cada um deles foi acondicionado, individualmente, em embalagens de filme-papel grau cirúrgico.

Todos os corpos de prova foram submetidos ao processo de esterilização em esterilizador por óxido de etileno da Sercon Ind. Com. Ap. Méd. Hosp. Ltda., modelo HSE 39/40 HETO 3000, com a mistura gasosa de óxido de 
etileno e diclorofluormetano na proporção 12:88 (Oxifume ${ }^{\circledR} 12$ ), com concentração de $600 \mathrm{mg} / \mathrm{L}$, à temperatura de $55^{\circ} \mathrm{C}$, umidade relativa de $60 \%$, durante 3 horas de exposição (Kereluk, Gammon, Lloyd, 1970a; Kereluk, Gammon, Lloyd, 1970b; Perkins, 1983; Farmacopéia Brasileira, 1988).

Após cada ciclo de reprocessamento, foram retiradas 10 unidades representativas de cada corpo de prova para serem submetidas aos testes de contagem microbiana por técnica de semeadura "pour plate", testes de esterilidade por inoculação direta e indireta, avaliação da toxicidade in vitro em cultura celular, microscopia eletrônica de varredura e observação macroscópica da integridade física, conforme mencionado em literatura (Tuominen, Keskimen, Rosenberg, 1988; Freshney, 1997; British Pharmacopoeia, 1999; European Pharmacopoeia, 1999; United States Pharmacopeia, 2000). Ao todo, foram

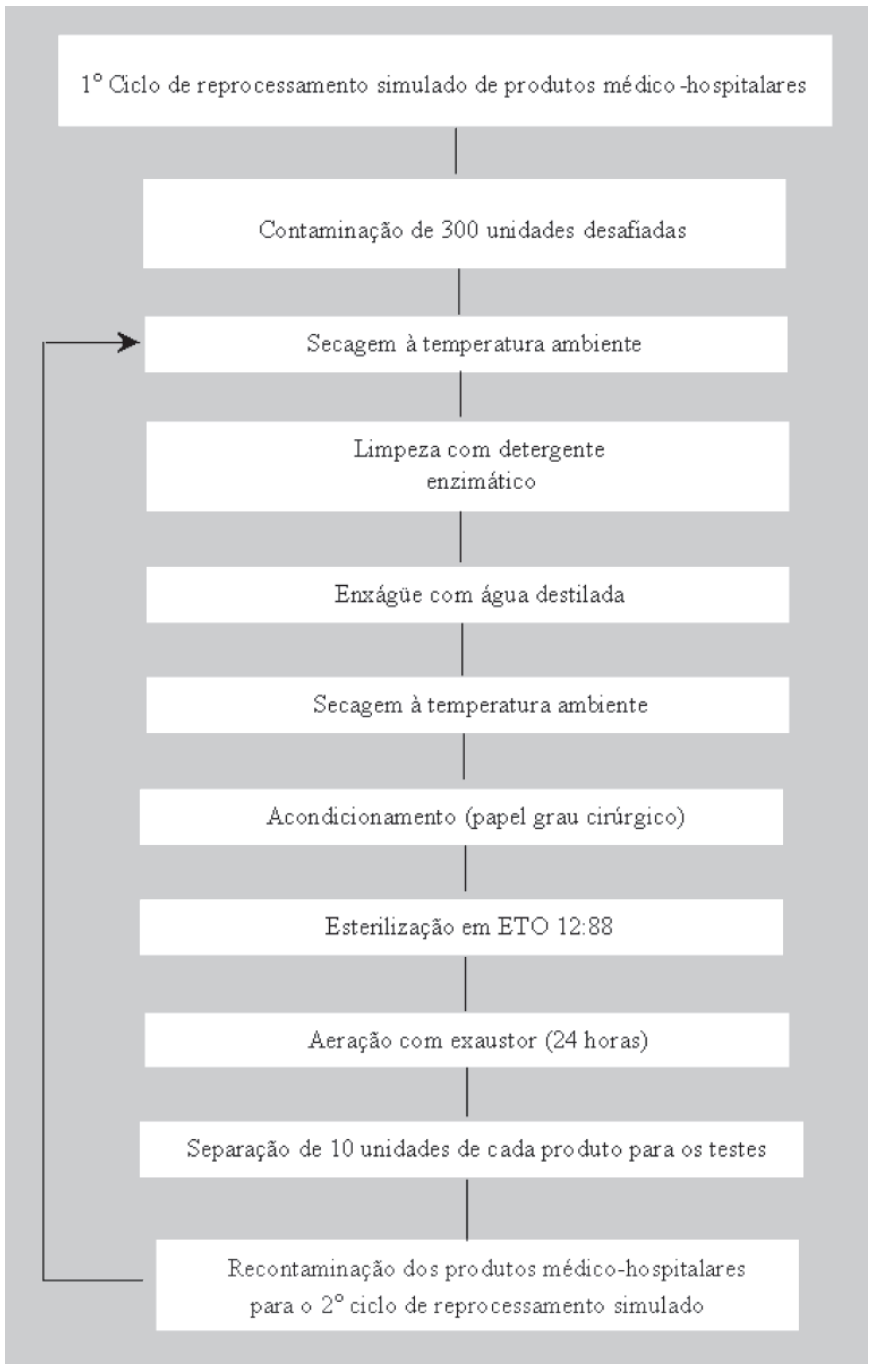

FIGURA 1 - Fluxograma das etapas de reprocessamentos simulados dos corpos de prova contaminados intencionalmente com Bacillus subtilis var. niger ATCC 9372.
10 ciclos de reprocessamentos, seguindo as etapas de inoculação de carga microbiana, secagem, limpeza e enxágüe, secagem, acondicionamento, esterilização e aeração com exaustor (Figura 1).

\section{Desafio com endotoxina bacteriana}

Trabalhou-se com a endotoxina da Escherichia coli, cepa O55:B5, adquirida da Charles River Endosafe ${ }^{\circledR}$, contendo $500 \mathrm{ng}$ de endotoxina liofilizada. O reagente LAL empregado na determinação quantitativa de endotoxina pelo método KTA (análise cinética turbidimétrica), com sensibilidade $\lambda=0,06 \mathrm{UE} / \mathrm{mL}$, foi adquirido do mesmo fornecedor da endotoxina.

Após reconstituição, conforme indicado pelo fornecedor da endotoxina bacteriana liofilizada, obteve-se dispersão de $2000 \mathrm{UE} / \mathrm{mL}$. Partindo-se desta, foram inoculados os corpos de prova com $0,1 \mathrm{~mL}$ (200 UE). As unidades inoculadas ficaram dispostas em suporte de aço inoxidável para secagem em estufa a $38 \pm 2{ }^{\circ} \mathrm{C}$, durante 7 dias.

Após secagem, acondicionou-se individualmente em embalagens do tipo filme-papel grau cirúrgico, sendo em

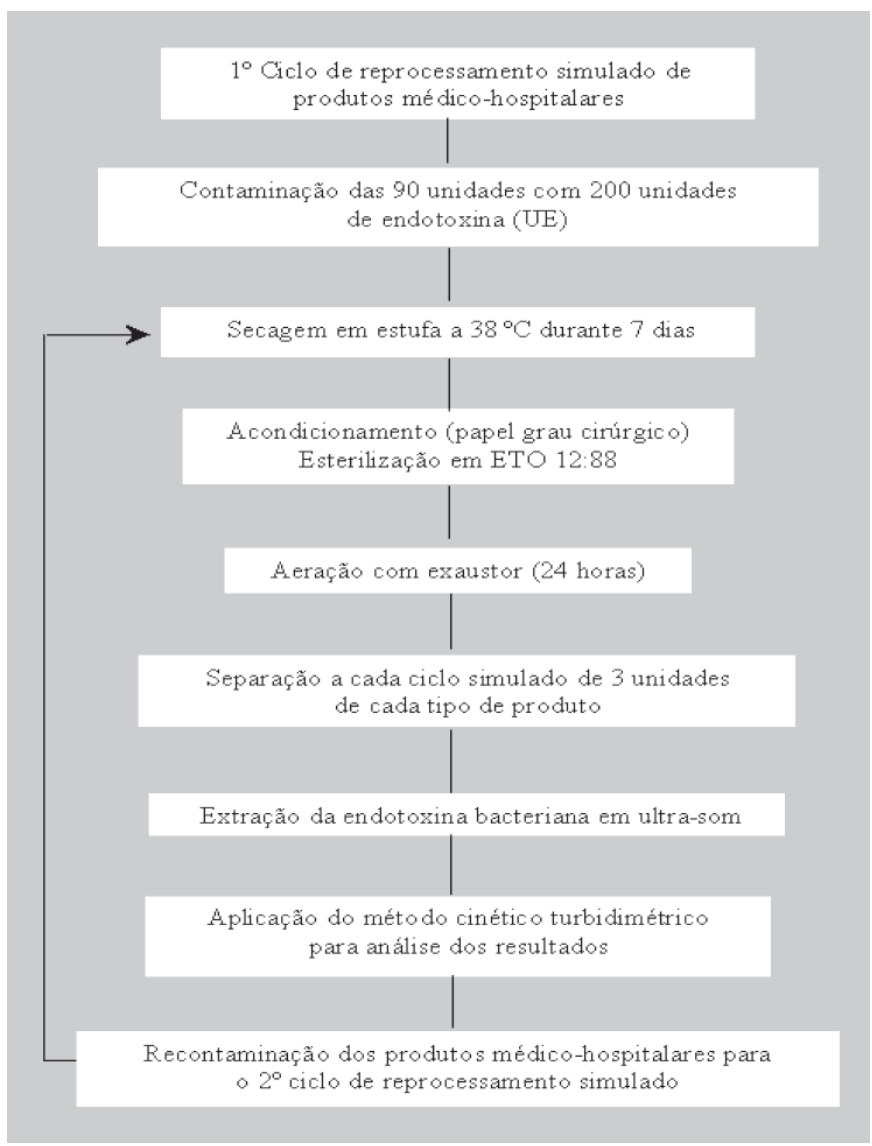

FIGURA 2 - Fluxograma das etapas de reprocesssamentos simulados dos corpos de prova contaminados intencionalmente com endotoxina bacteriana. 
seguida submetidos aos ciclos de reprocessamentos simulados com exposição à mistura gasosa mencionada anteriormente, mantendo-se os mesmos parâmetros de esterilização.

Três unidades de cada corpo de prova foram retiradas após cada ciclo de reprocessamento para avaliação pelo método quantitativo cinético turbidimétrico de endotoxina bacteriana in vitro, totalizando dez ciclos de reprocessamentos (Figura 2). Os corpos de prova selecionados foram submetidos a técnica extrativa para recuperar a endotoxina inoculada, empregando-se solução extrativa esterilizada, preparada a partir de solução estoque a $1 \%$ (p/ v) de lauril sulfato de sódio em solução fisiológica apirogênica, conforme técnica de extração mencionada em literatura (Twohy, Duran, Peeler, 1986).

O método cinético turbidimétrico empregado utilizou endotoxina bacteriana que, depois de reconstituída, conforme orientação do fabricante, apresentou concentração de $50 \mathrm{UE} / \mathrm{mL}$. Partindo-se desta, foram preparadas três diluições decimais seriadas com água estéril e apirogênica, obtendo soluções de 5,0,0,5 e 0,05 UE/mL, utilizadas para obter a curva padrão de referência (Cooper, Jornan, 2001; Roslansky, Dawson, Novitsky, 1991).
Alíquotas de $0,1 \mathrm{~mL}$ dos controles positivos, assim como de cada corpo de prova e dos controles negativos, foram transferidas para placa Elisa, em duplicata. Após agitação de 10 minutos a $37^{\circ} \mathrm{C}$ no leitor Elisa, retirou-se a placa. O mesmo volume do reagente LAL para KTA, reconstituído conforme fornecedor, foi transferido para cada poço da placa Elisa na qual estavam as amostras desafiadas e os controles positivos e negativos (Norvitsky, Schmidt-Gengenbach, Remillard, 1986; Zijlstra et al., 1997; British Pharmacopoeia, 1999; European Pharmacopoeia, 1999; United States Pharmacopeia, 2000). Efetuou-se leitura dos resultados durante 60 minutos a $37^{\circ} \mathrm{C}$, em leitor elisa (modelo Bio Tek ELx808UI).

\section{RESULTADOS}

Os resultados obtidos, referentes ao desafio simulado com a cepa microbiana Bacillus subtilis, estão representados abaixo, conforme Figuras 3, 4, 5, 6, 7, 8 e 9, assim como nas Tabelas I e II. Com relação aos resultados do desafio simulado com endotoxina bacteriana, estes estão apresentados nas Figuras 10, 11 e 12.

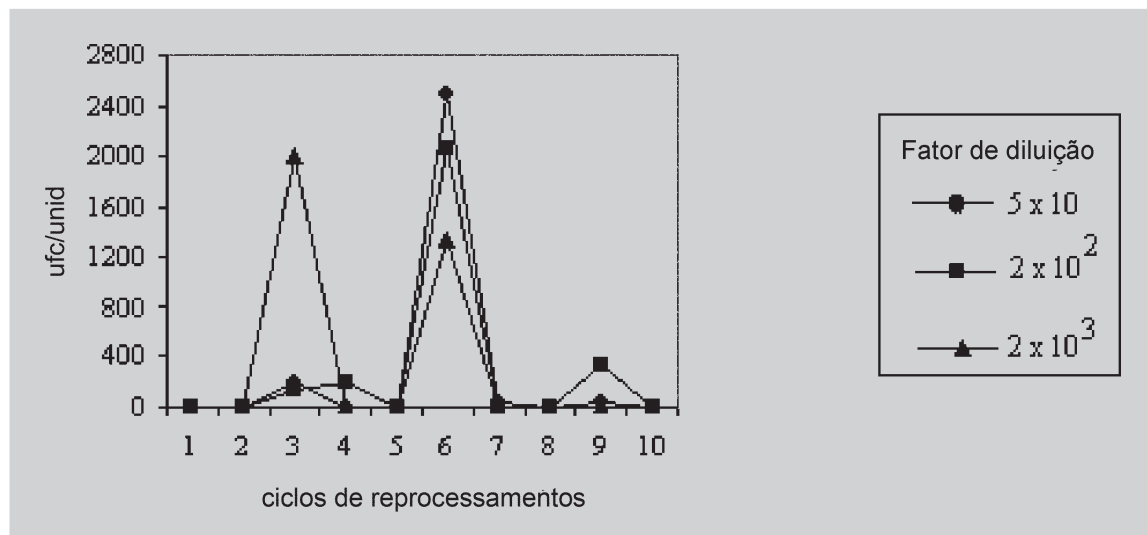

FIGURA 3 - Contagem microbiana dos cateteres intravenosos de uso único submetidos a dez ciclos de reprocessamentos simulados.

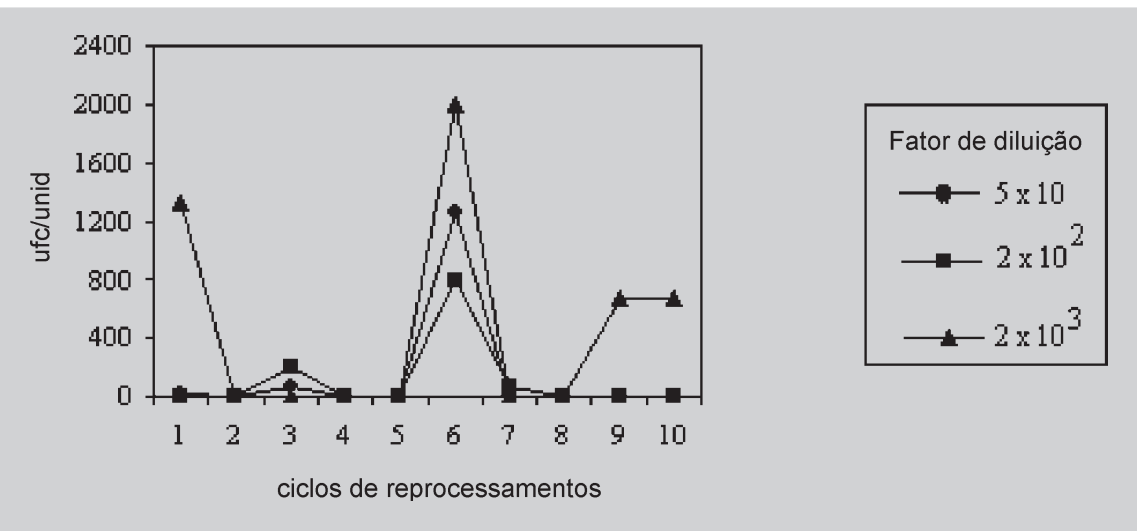

FIGURA 4 - Contagem microbiana das torneiras três vias de uso único submetidas a dez ciclos de reprocessamentos simulados. 


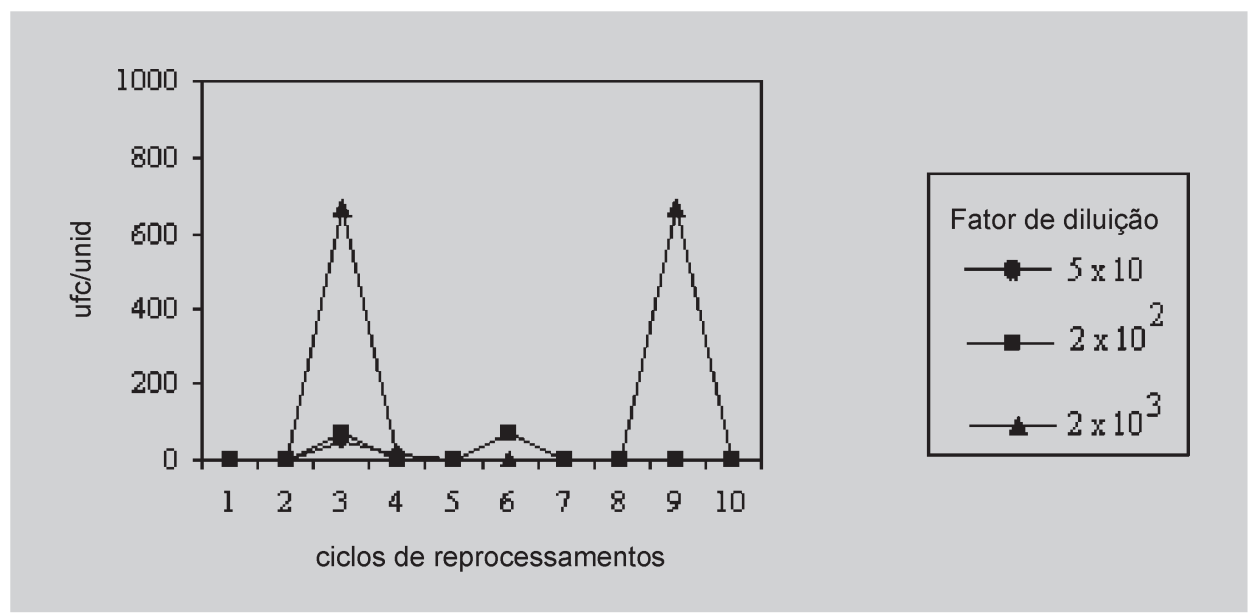

FIGURA 5 - Contagem microbiana dos tubos de traqueostomia de uso único submetidos a dez ciclos de reprocessamentos simulados.

TABELA I - Teste de esterilidade por inoculação direta após dez ciclos de reprocessamentos simulados dos corpos de prova contaminados com a cepa microbiana.

\begin{tabular}{|c|c|c|c|c|}
\hline \multirow[b]{2}{*}{ Ciclos } & \multirow[b]{2}{*}{ Meio/Temp. $\left({ }^{\circ} \mathrm{C}\right)$} & \multicolumn{3}{|c|}{ Produtos } \\
\hline & & Cateter & Torneira & Tubo \\
\hline \multirow[t]{2}{*}{1} & $\mathrm{TSB} / 22,5$ & - & $+5 \mathrm{a}$ & $+2 \mathrm{a}$ \\
\hline & $\mathrm{TG} / 32,5$ & $++^{5 a}$ & - & _ \\
\hline \multirow[t]{2}{*}{2} & $\mathrm{TSB} / 22,5$ & $+2 \mathrm{a}$ & $+5 \mathrm{a}$ & $+2 \mathrm{a}$ \\
\hline & $\mathrm{TG} / 32,5$ & $+^{1 \mathrm{a}}$ & $+2 \mathrm{a}$ & - \\
\hline \multirow[t]{2}{*}{3} & $\mathrm{TSB} / 22,5$ & $+4 \mathrm{a}$ & - & $+4 a$ \\
\hline & TG/32,5 & $+{ }^{11 \mathrm{a}}$ & - & $+4 \mathrm{a}$ \\
\hline \multirow[t]{2}{*}{4} & $\mathrm{TSB} / 22,5$ & - & - & - \\
\hline & $\mathrm{TG} / 32,5$ & - & - & - \\
\hline \multirow[t]{2}{*}{5} & $\mathrm{TSB} / 22,5$ & - & - & - \\
\hline & TG/32,5 & - & - & - \\
\hline \multirow[t]{2}{*}{6} & $\mathrm{TSB} / 22,5$ & $+5 \mathrm{a}$ & $+^{2 \mathrm{a}}$ & $+^{5 a}$ \\
\hline & $\mathrm{TG} / 32,5$ & $+^{5 \mathrm{a}}$ & $+^{2 \mathrm{a}}$ & $+^{5 a}$ \\
\hline \multirow[t]{2}{*}{7} & $\mathrm{TSB} / 22,5$ & - & - & - \\
\hline & TG/32,5 & - & - & - \\
\hline \multirow[t]{2}{*}{8} & $\mathrm{TSB} / 22,5$ & - & - & - \\
\hline & TG/32,5 & - & - & - \\
\hline \multirow[t]{2}{*}{9} & $\mathrm{TSB} / 22,5$ & - & - & - \\
\hline & $\mathrm{TG} / 32,5$ & - & - & - \\
\hline \multirow[t]{2}{*}{10} & $\mathrm{TSB} / 22,5$ & - & - & - \\
\hline & $\mathrm{TG} / 32,5$ & - & - & - \\
\hline
\end{tabular}

Nota: TSB: Meio caseína de soja; TG: Meio tioglicolato fluido; Meio/Temp.: Meio de cultura/Temperatura; Cateter: Cateter intravenoso; Torneira: Torneira três vias; Tubo: Tubo de traqueostomia; $+^{\mathrm{a}}$ : Verificado crescimento microbiano após (a) dias de incubação; -: Não verificado crescimento microbiano durante o período de incubação.
TABELA II - Teste de esterilidade por inoculação indireta após dez ciclos de reprocessamentos simulados dos corpos de prova contaminados com a cepa microbiana.

\begin{tabular}{|c|c|c|c|c|}
\hline \multirow[b]{2}{*}{ Ciclos } & \multirow[b]{2}{*}{ Meio/Temp. $\left({ }^{\circ} \mathrm{C}\right)$} & \multicolumn{3}{|c|}{ Produtos } \\
\hline & & Cateter & Torneira & Tubo \\
\hline \multirow[t]{2}{*}{1} & $\mathrm{TSB} / 22,5$ & - & - & - \\
\hline & $\mathrm{TG} / 32,5$ & - & - & - \\
\hline \multirow[t]{2}{*}{2} & $\mathrm{TSB} / 22,5$ & - & - & $+5 a$ \\
\hline & $\mathrm{TG} / 32,5$ & - & - & - \\
\hline \multirow[t]{2}{*}{3} & $\mathrm{TSB} / 22,5$ & - & - & $+2 \mathrm{a}$ \\
\hline & $\mathrm{TG} / 32,5$ & - & - & - \\
\hline \multirow[t]{2}{*}{4} & $\mathrm{TSB} / 22,5$ & - & - & - \\
\hline & $\mathrm{TG} / 32,5$ & - & - & - \\
\hline \multirow[t]{2}{*}{5} & $\mathrm{TSB} / 22,5$ & - & - & - \\
\hline & $\mathrm{TG} / 32,5$ & - & - & - \\
\hline \multirow[t]{2}{*}{6} & $\mathrm{TSB} / 22,5$ & $+2 \mathrm{a}$ & $+2 \mathrm{a}$ & $+2 \mathrm{a}$ \\
\hline & $\mathrm{TG} / 32,5$ & $+2 \mathrm{a}$ & $+2 \mathrm{a}$ & - \\
\hline \multirow[t]{2}{*}{7} & $\mathrm{TSB} / 22,5$ & - & - & - \\
\hline & TG/32,5 & - & - & - \\
\hline \multirow[t]{2}{*}{8} & $\mathrm{TSB} / 22,5$ & - & - & - \\
\hline & $\mathrm{TG} / 32,5$ & - & - & - \\
\hline \multirow[t]{2}{*}{9} & $\mathrm{TSB} / 22,5$ & - & - & - \\
\hline & $\mathrm{TG} / 32,5$ & - & - & - \\
\hline \multirow[t]{2}{*}{10} & $\mathrm{TSB} / 22,5$ & - & - & - \\
\hline & TG/32,5 & - & - & - \\
\hline
\end{tabular}

Nota: TSB: Meio caseína de soja; TG: Meio tioglicolato fluido; Meio/Temp.: Meio de cultura/Temperatura; Cateter: Cateter intravenoso; Torneira: Torneira três vias; Tubo: Tubo de traqueostomia; $+^{\mathrm{a}}$ : Verificado crescimento microbiano após (a) dias de incubação; -: Não verificado crescimento microbiano durante o período de incubação. 


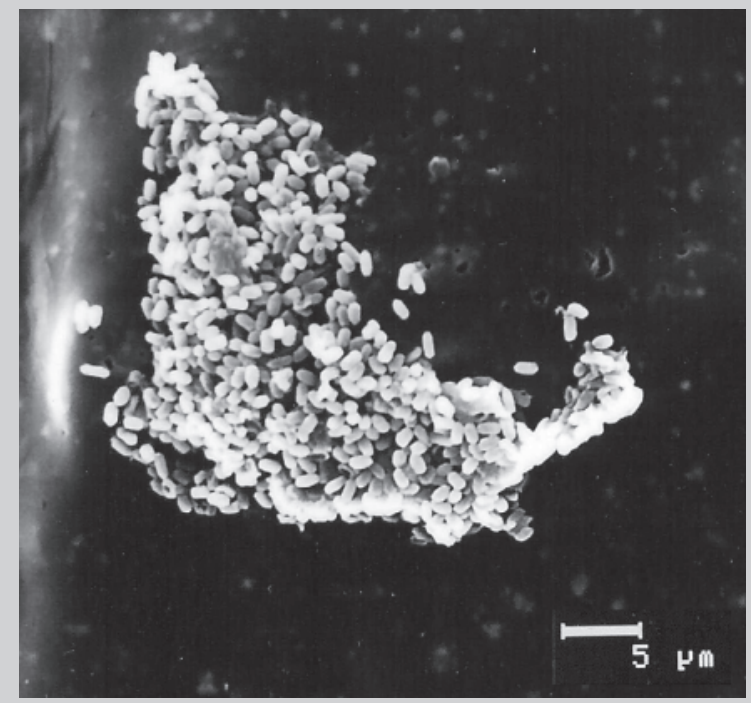

FIGURA 6 - Eletromicrografia de varredura da superfície interna de cateter intravenoso em poliuretano, reprocessado dez vezes, mostrando aglomerado de Bacillus subtilis aderidos ao "lumen" do cateter intravenoso.

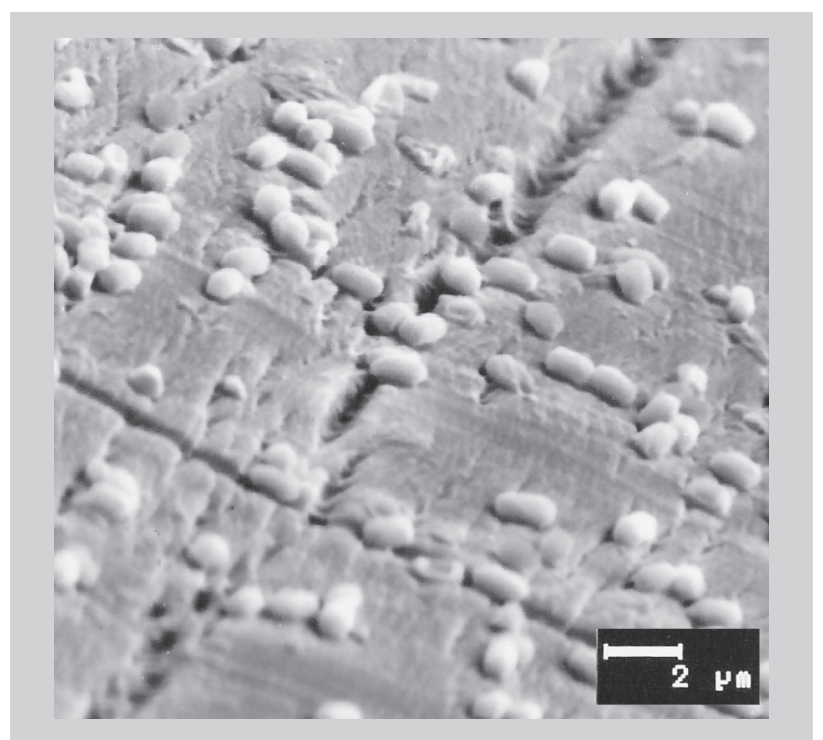

FIGURA 7 - Eletromicrografia de varredura da superfície interna de torneira três vias em policarbonato, reprocessada dez vezes, apresentando fendas e orifícios na superfície, com presença de Bacillus subtilis.

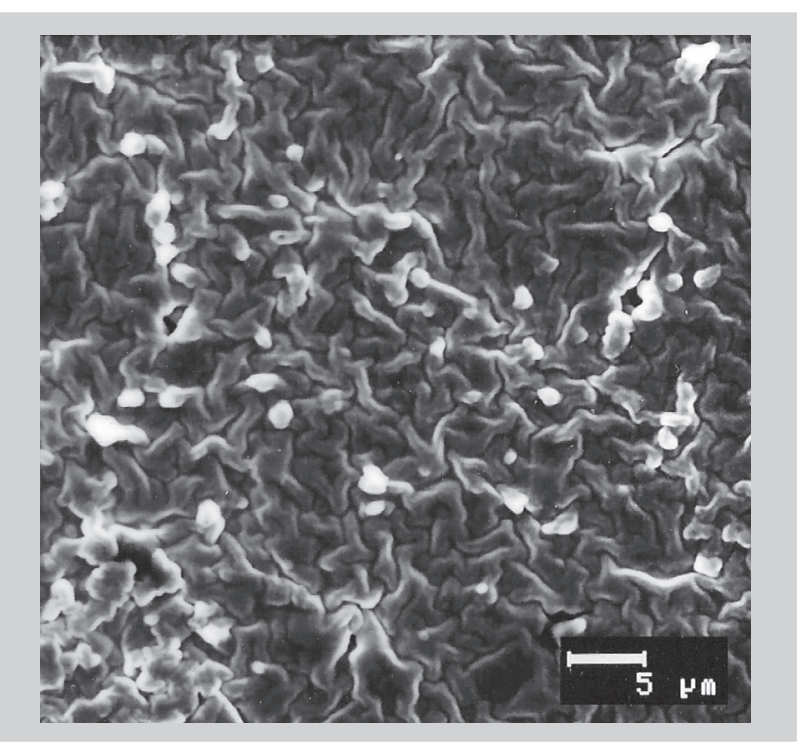

FIGURA 8 - Eletromicrografia de varredura da superfície externa do balonete de tubo de traqueostomia em poli (cloreto de vinila), reprocessado dez vezes, mostrando presença de Bacillus subtilis aderidos à superfície rugosa.

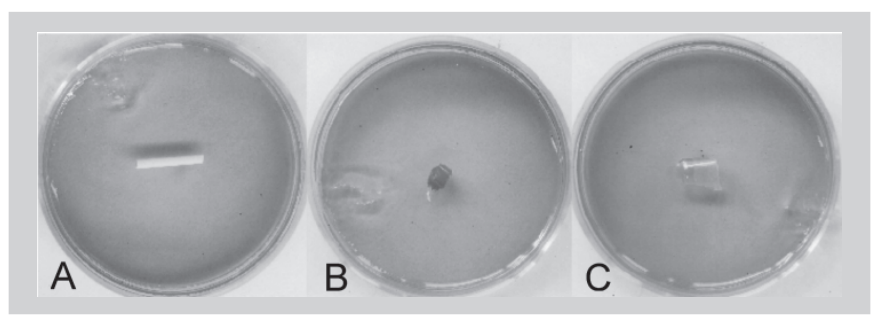

FIGURA 9 - Teste de toxicidade in vitro dos corpos de prova após o $10^{\circ}$ ciclo de reprocessamento: (A) cateter intravenoso; (B) torneira três vias; (C) tubo de traqueostomia.

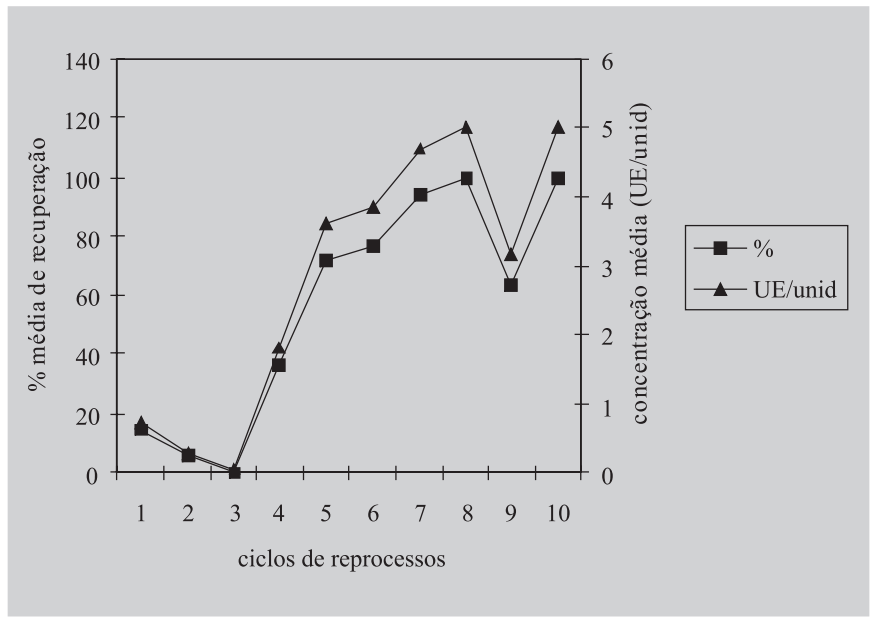

FIGURA 10 - Valores médios de concentração e porcentagem de recuperação de endotoxina bacteriana em cateteres intravenosos submetidos a dez reprocessamentos simulados. 


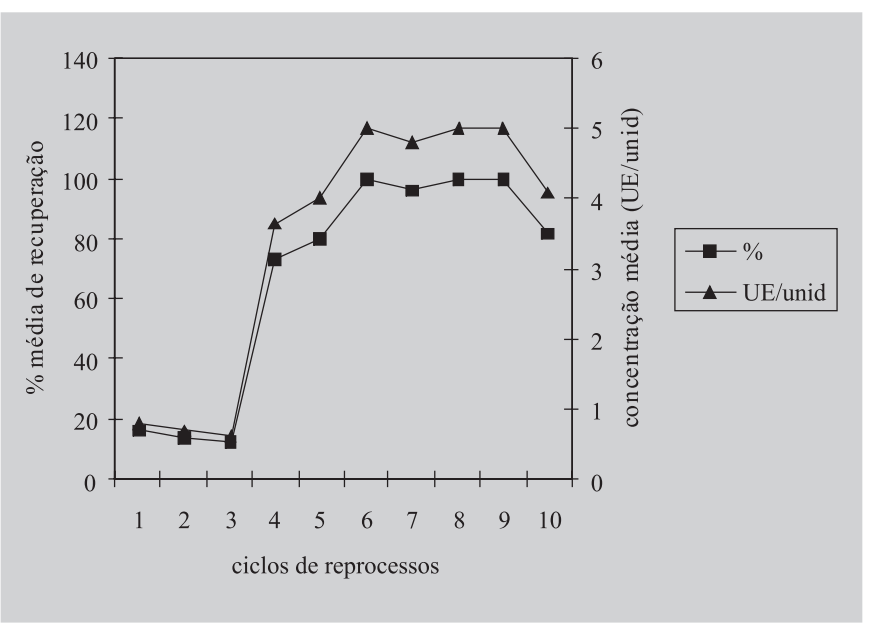

FIGURA 11 - Valores médios de concentração e porcentagem de recuperação de endotoxina bacteriana em torneiras três vias submetidas a dez reprocessamentos simulados.

\section{DISCUSSÃO}

Conforme contagem microbiana pela técnica "pour plate" e os testes de esterilidade por inoculação direta e indireta representados nas Figuras 3, 4 e 5 e nas Tabelas I e II, respectivamente, é possível observar que, mesmo após processo de limpeza e esterilização com a mistura de óxido de etileno/CFC 12:88, se verificou presença de carga microbiana até $10^{3} \mathrm{ufc} /$ unidade, sendo confirmado também macroscopicamente pelo crescimento microbiano característico de $B$. subtilis, nos testes de esterilidade direto e indireto.

No desafio com B. subtilis, os ciclos de reprocessamentos que mais apresentaram contaminação foram os $3^{\circ}$ e $6^{\circ}$ ciclos, destacando-se os cateteres e tubos de traqueostomia no $3^{\circ}$ ciclo, e cateteres e torneiras três vias no $6^{\circ}$ ciclo, conforme as Figuras 3,4 e 5 e as Tabelas I e II.

A incidência de contaminação nos $3^{\circ}$ e $6^{\circ}$ ciclos retrata que o processo de limpeza é factível a falhas dentro de um reprocessamento, seja ele manual ou mecanizado, pois essa ocorrência pode ser verificada devido ao grau de dificuldade apresentado pelos produtos médico-hospitalares em sua estrutura física, uma vez que muitos deles possuem lúmens estreitos, que dificultam a eliminação dos resíduos biológicos.

Quando a limpeza não alcança a eficácia desejada, isso reflete no processo de esterilização, pois os resíduos presentes protegem, de certa forma, a carga microbiana da ação do agente esterilizante (Pinto, Graziano, 2000).

As Figuras 6, 7 e 8 representam a microscopia eletrônica de varredura realizada nos três tipos de corpos de

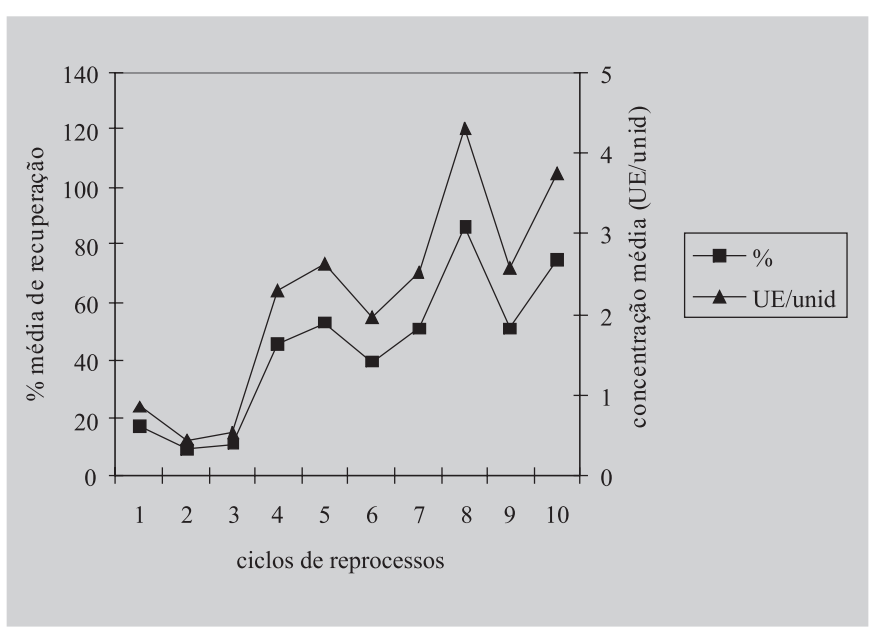

FIGURA 12 - Valores médios de concentração e porcentagem de recuperação de endotoxina bacteriana em tubos de traqueostomia submetidos a dez reprocessamentos simulados.

prova, cujas eletromicrografias expõem a presença $\operatorname{dos} B$. subtilis aderidos à superfície desses produtos após o décimo reprocesso. Essa presença de bacilos aderidos à superfície dos corpos de prova mostra que o desgaste da estrutura polimérica desses materiais contribuiu para reter esses resíduos biológicos. Tal fato, de certa forma, contradiz o que vem sendo cogitado sobre a garantia do reprocessamento de produtos fabricados para uso único.

As evidências representadas nos resultados dos testes aplicados confirmaram que durante a limpeza e esterilização desses produtos reprocessados ocorreram falhas, em razão da carga viável presente na contagem microbiana. Todavia, o teste de citotoxicidade in vitro, conforme Figura 9, não apresentou formação de halo, enfatizando a ausência de reatividade biológica significativa, conforme literatura (United States Pharmacopeia, 2000). Isso justifica que o processo de aeração empregado alcançou o objetivo almejado quanto à redução de resíduos tóxicos do gás esterilizante, que poderia provocar reações de toxicidade.

A avaliação macroscópica de alguns corpos de prova apresentou no decorrer do experimento desgaste na integridade física desses materiais, enfatizando com isso que esses produtos são fabricados com a finalidade de se utilizar uma única vez.

Com relação aos resultados do desafio com endotoxina bacteriana, foi possível observar que nos três primeiros ciclos de reprocessamentos houve queda significativa para os três tipos de corpos de prova, porém com os sucessivos ciclos, as porcentagens de recuperação foram aumentando progressivamente. A Figura 10 apre- 
senta índice de recuperação de $100 \%$ de endotoxina bacteriana no décimo ciclo de reprocessamento para os cateteres intravenosos, sendo provável que tal índice tenha atingido esse patamar devido ao calibre estreito do lúmen, que dificulta a ação do agente esterilizante.

Já as torneiras três vias e os tubos de traqueostomia, conforme Figuras 11 e 12, apresentaram, após o décimo ciclo de reprocessamento, valores de recuperação, respectivamente, de $82 \%$ e $75 \%$, aproximadamente. Esses valores também são considerados significativos, uma vez que todos os produtos foram submetidos a três horas de esterilização em cada ciclo de reprocesso. Logo, altos índices de endotoxina bacteriana presentes nos corpos de prova demonstraram que a ação do agente esterilizante não foi suficiente para inativar sua ação após sucessivos reprocessos.

\section{CONCLUSÃO}

Com base nos resultados obtidos, concluiu-se que os consecutivos reprocessamentos do desafio com $B$. subtilis, após processos de limpeza e esterilização, reduziram 4 ciclos log em relação à carga inicial inoculada ( $10^{7}$ ufc/unidade), não assegurando ausência de carga microbiana após reprocessamentos.

Para o desafio com endotoxina bacteriana, verificouse que o óxido de etileno, apesar da sua ação alquilante, não pode ser considerado um agente despirogenizante eficaz. Logo, os desafios simulados em corpos de prova retrataram a insegurança gerada pelo reprocessamento de produtos médico-hospitalares fabricados para uso único, uma vez que há a necessidade de validar e padronizar para cada produto um processo de limpeza, pois estes apresentam características físicas distintas.

Outro fato a ser considerado está relacionado com o número de vezes que tal produto poderá ser reprocessado e se o reprocesso não trará mais custos do que economia para o hospital, assim como danos ao paciente. Com base neste fato, outros estudos relacionados a este assunto devem ser desenvolvidos com a finalidade de obter maior segurança quanto a prática hospitalar de reprocessar produtos médico-hospitalares fabricados para serem utilizados e, em seguida, descartados, pois só assim será possível adotar-se postura firme sobre tal prática.

\section{ABSTRACT \\ Simulated reuse of single use medical devices submitted to ethylene oxide sterilization}

The risk/benefit associated with reprocessing practice of single use medical devices had been evaluated through two simulated challenges: one with spores of Bacillus subtilis and other with bacterial endotoxin of the Escherichia coli, in specimen samples represented by intravenous catheters, three-way stopcocks and tracheostomy tubes. The selected devices (300 units) were intentionally contaminated with $\mathrm{B}$. subtilis $\left(10^{7}\right.$ cfu/device) and other group of 90 devices contaminated with bacterial endotoxin (200 EU/device). The B. subtilis contaminated specimen samples had been washed, rinsed, dried and sterilized with ETO/ CFC 12:88. Those contaminated with bacterial endotoxin had been submitted to drying, repacking and sterilization. After each cycle, ten units, contaminated with B. subtilis, had been evaluated by microbial counting test, sterility test, in vitro cytotoxicity and scanning electron microscopy. Those contaminated with bacterial endotoxin, three units of each specimen sample, had been submitted to the turbidimetric test, after each cycle. Amongst the units challenged with $\mathrm{B}$. subtilis, viable load of $10^{3} \mathrm{cfu}$ was verified, surface damages were noticed on the specimen samples after tenth reprocessing cycles, but no toxicity was observed. In the other challenge, a gradual increase in recovered percentage of bacterial endotoxin was verified. Taking into consideration the obtained results, we do not recommend reprocessing of single use medical devices.

UNITERMS: Medical devices. Reuse. Reprocess. Bacillus subtilis. Ethylene oxide. Bacterial endotoxina.

\section{AGRADECIMENTOS}

Os autores gostariam de agradecer à farmacêutica Mônica Komiyama, da Fundação para o Remédio Popular (FURP), pela sua colaboração nas análises do desafio com endotoxina bacteriana. Ao Conselho Nacional de Desenvolvimento Científico e Tecnológico $(\mathrm{CNPq})$ e à Fundação Fipfarma, pelo auxílio financeiro.

\section{REFERÊNCIAS BIBLIOGRÁFICAS}

ALFA, M.J.; NEMES R. Inadequacy of manual cleaning for reprocessing single-use, triple-lumen sphinctrertomes: Simulated-use testing comparing manual with automated cleaning methods. Infect. Control Hosp. Epidemiol.,Thorefare, v.31, n.4, p.193-207, 2003.

BERENGER, S.J.; FERGUSON, B.J.K. Reuse of single-use medical devices: how often does this still occur in Australia? Med. J. Aust., Sidney, v.180, n. 1, p.46-47, 2004. 
BLOMSTRÖM-LUNDQVIST, C. Reuse of catheter for invasive electrophysiological procedures. Eur. Heart J., London, v.1, suppl.G, p.15-19, 1999.

BRITISH Pharmacopoeia. London: Her Majesty's Stationary Office, 1999. v.2, pt.2., p.A251-A254, A342-A347.

COOPER, J.F.; JORDAN, F.T. Starting a kinetic LAL system. LAL Times, v.7, n.3, p.1-5, 2000. Disponível em: $<$ http://www.criver.com>. Acesso em: 13 out. 2001.

EUROPEAN Pharmacopoeia: supplement. 3.ed. Strasbourg: Council of Europe, 1999. p.25-29, 34, 41-49 (European treaty series, n. 50).

FARMACOPÉIA brasileira. 4.ed. São Paulo: Atheneu, 1988. pt.1, p.v.5.1.1-v.5.1.1.6, v.5.1.2, v.5.1.6-v.5.1.7.-3, x.1.1.1x.1.2.1.

FRESHNEY, R.I. Culture of animal cells: a manual of basic technique. 2.ed. New York: Alan R. Liss, 1987. 397p.

KERELUK, K.; GAMMON, R.A.; LLOYD, R.S. Microbiological aspects of ethylene oxide sterilization. III. Effects of humidity and water activity on the sporicidal activity of ethylene oxide. Appl. Microbiol., Baltimore, v.19, n.1, p.157-162, 1970a.

. Microbiological aspects of ethylene oxide sterilization. IV. Effects of thickness of polyethylene film on the sporicidal activity of ethylene oxide. Appl. Microbiol., Baltimore, v.19, n.1, p.163-165, 1970 b.

LACERDA, R.A.; SILVA, A. Limpeza dos artigos médicohospitalares. Rev. Paul. Hosp., São Paulo, v.40, n.5, 1992.

NOVITSKY, T.J.; SCHMIDT-GENGENBACH, J.; REMILLARD, J.F. Factors affecting recovery of endotoxin adsorbed to container surfaces. J. Parenter. Sci. Technol., Philadelphia, v.40, n.6, p.284-286, 1986.

PERKINS, J.J. Principles and methods of sterilization in health sciences. 2.ed. Springfield: Charles C. Thomas, 1983. p. 56-62, 327-341, 501-528.

PINTO, T.J.A., SAITO, T., IOSSIF, M. Ethylene oxide sterilization: III. Influence of carrier nature in a biological monitor performance. PDA J. Pharm. Sci. Technol., Bethesda, v.48, n.3, p.155-158, 1994.
PINTO, T.J.A.; GRAZIANO, K.U. Reprocessamento de artigos médicos-hospitalares de uso único. In: FERNANDES, A.T.; FERNANDES, M.O.V.; RIBEIRO FILHO, N., (Eds.). Infecção hospitalar e suas interfaces na área da saúde. São Paulo: Atheneu, 2000.p.1070-1077.

PINTO, T.J.A.; KANEKO, T.M.; OHARA, M.T. Controle biológico de qualidade de produtos farmacêuticos, correlatos e cosméticos. São Paulo: Atheneu, 2000. p.99-136, 168-200.

PINTO, T.J.A.; SAITO, T. Ethylene oxide sterilization. I. The influence of sporulation medium in the resistance of the sporos of Bacillus subtilis var. niger. Rev. Saúde Pública, Rio de Janeiro, v.26, n.6, p.379-383, 1992.

PLANTE, S.; STRAUSS, B.H.; GOULET, G.; WATSON, R.K.; CHISHOLM, R.J. Reuse of balloon catheters for coronary angioplasty: a potential cost-saving strategy? JACC, Brussels, v.24, n.6, p.1475-1481, 1994.

ROSLANSKY, P.F.; DAWSON, M.E.; NOVITSKY, T.J. Plastics, endotoxins, and Limulus amebocyte lysate test. J. Parenter. Sci. Technol., Philadelphia, v.45, n.2, p.8387, 1991.

TUOMINEN, M.K.; KESKIMEN, K.; ROSENBERG, H. Scanning electron microscopic examination of resterilized 29-gauge spinal needles. Anesthesiology, Hagerstown, v.69, p. 123-125, 1988.

TWOHY, C.W.; DURAN, A.P.; PEELER, J.T. Extraction of bacterial endotoxin from medical devices. J. Parenter. Sci. Technol., Philadelphia, v.40, n.6, p.287-291, 1986.

UNITED States Pharmacopeia. 24.ed. Rockville: United States Pharmacopeial Convention, 2000. p.1851, 2161, 1811, 1816, 1818-1823, 1829-1835.

ZIJLSTRA, S.; GERKEN, P.; RECHIN, C.; WORTMANN, R. Validation of the Limulus amebocyte lysate (LAL) test for routine PET radiopharmaceuticals. Appl. Radiat. Isot., Oxford, v.48, n.1, p.51-54, 1997.

Recebido para publicação em 25 de outubro de 2004 Aceito para publicação em 06 de abril de 2005 